\title{
A new vector for efficient gene targeting to the pyrG locus in Aspergillus niger
}

\author{
Mark Arentshorst ${ }^{*}$, Ellen L Lagendijk and Arthur FJ Ram
}

\begin{abstract}
Background: The possibility for efficient gene targeting for the controlled integration of DNA constructs is an important tool in fungal genetics.

Findings: In this study, we report a new targeting vector based on the pyrG marker in Aspergillus niger. The DNA sequence to be targeted is surrounded by two fragments of the pyrG gene to allow homologous recombination of the recombinant DNA at the pyrG locus. The $5^{\prime}$ end of the targeting cassette contains a non-functional truncated pyrG open reading frame (first 112 bases deleted) and the $3^{\prime}$ untranslated region ( $3^{\prime}$ UTR). At the $3^{\prime}$ end, the targeting cassette consists of the $3^{\prime}$ flanking region of the pyrG gene. A unique Notl site between the flanks allows the insertion of a gene of interest. The linearized targeting cassette is transformed to the A. niger pyrG mutant strain AB4.1 or a derivative thereof. By using a constitutively expressed luciferase reporter gene (m/uc) as an example, it is shown that the targeting system is efficient as 4 out of 6 (67\%) AB4.1 transformants and 51 out of 66 (77\%) MA169.4 (ku70-) transformants contained the reporter gene at the pyrG locus. A luciferase (lux) activity assay, performed with independently obtained transformants in which the mluc reporter was integrated at the pyrG locus, showed comparable and reproducible lux activities.

Conclusion: The new pyrG targeting vector is an important improvement to the existing method for gene targeting in A. niger. Although the vector is specific for A. niger, the presented design and approach is easily applicable for constructing integration vectors for other fungi.
\end{abstract}

Keywords: Reporter gene, Luciferase activity, Promoter analysis

\section{Finding}

The pyrG gene of Aspergillus niger (An12g03570) is homologous to the Saccharomyces cerevisiae URA3 gene. In A. niger, as well as in other fungi, the pyrG marker is popular because it is a stringent auxotrophic marker which can be fully supplemented with uridine or uracil [1-3]. Another advantage of the pyrG marker over other auxotrophic markers is that it is counter selectable and pyrG mutants can be obtained by isolating 5-fluoro-orotic resistant mutants $[4,5]$. The pyrG mutant strain AB4.1 is often used in $A$. niger genetics [1], for instance in numerous studies to create gene deletion mutants using the pyrG gene of $A$. oryzae as a heterologous marker, initially developed by de Ruijter-Jacobs et al. [6]. The A. niger $\Delta k u 70, p y r G^{-}$mutant MA70.15 [7] and $k u 70^{-}, p y r G^{-}$mutant MA169.4 [8], are derived from AB4.1. Sequence analysis of the pyrG gene in

\footnotetext{
* Correspondence: m.arentshorst@biology.leidenuniv.nl

Molecular Microbiology and Biotechnology, Institute of Biology Leiden, Leiden University, Sylviusweg 72, 2333 BE Leiden, The Netherlands
}

the AB4.1 mutant showed a deletion of a cytosine at position $378 \mathrm{bp}$ in the pyrG gene, causing an out of frame mutation after 103 amino acids. The AB4.1 mutant has been used to set up a system for targeted integration of e.g. reporter constructs to the pyrG locus [9]. This system, referred to as the pyrG* (pyrG star) system, makes use of the AB4.1 mutant, in combination with a plasmid based mutated $A$. niger pyrG gene. The mutation in the plasmid based $p y r G$ gene was introduced by filling in the BamHI restriction site (position $828 \mathrm{bp}$ in the pyrG ORF) that is present in the protein-coding region of the gene, causing a frame shift. The vector containing the $\operatorname{pyr} G^{\text {BamHI }}$ will not be functional when ectopically integrated and will therefore not give rise to uridine prototrophic transformants. However, targeted integration of the $\operatorname{pyrG}^{\text {Bam } \mathrm{HI}}$ at the pyrG locus of strain AB4.1 via a single cross over will result in the integration of the vector at the pyrG locus (Figure 1). The pyr $G^{*}$ system has been successfully used in several studies for the targeted integration of reporters in 


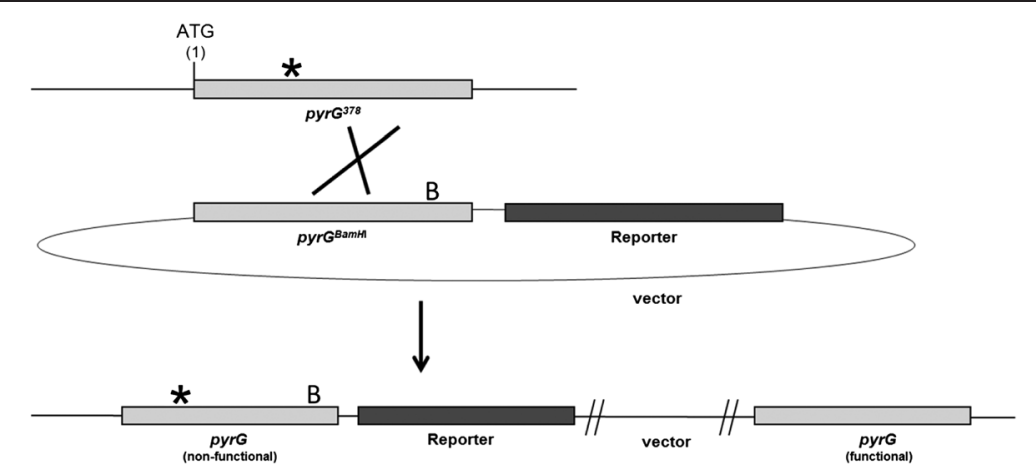

Figure 1 Schematic representation of integration of a reporter construct after a single crossover event using the $p y r G^{*}$ targeting system. This system was described previously by van Gorcom and van den Hondel [9]. Strain AB4.1 contains a base deletion at position 378 in the pyrG open reading frame indicated with $a^{*}$. A circular plasmid containing the reporter gene and the mutated pyrG gene (pyrG ${ }^{\text {Bam } H}$ ) is transformed to AB4.1 and a single cross over at the pyrG locus leads to integration into the genome. Note that the entire vector is integrated in this system. The pyrG $\mathrm{G}^{*}$ fragment is a located on a $3.8 \mathrm{~kb}$ Xbal subclone and can be inserted in a vector for targeted integration.

gene expression studies [10,11], or for the controlled integration of expression cassettes [12] and GFP-fusion proteins [13].

However, there are certain drawbacks of using the pyrG* method. Transformation frequencies are on average 10 to 20 times lower compared to regular pyrG transformations, often resulting in only one or two transformants per transformation. In addition, the percentage of successful integration of the reporter construct, varying between 10 to $50 \%$, is rather low, probably due to a recombination or repair event that restores the mutation in the pyrG gene in AB4.1. Another disadvantage of the $p y r G^{*}$ system is that after targeted integration, two pyrG repeats are present around the construct, making the loss of the reporter construct via a loop out event possible (Figure 1). Finally, despite the well established positive effect on gene targeting efficiencies in $k u 70$ mutants $[7,8]$, we noticed that deletion of the $k u 70$ gene did not improve transformation or targeted integration frequencies of the pyrG* plasmid. The reason for this is not known and systematic studies to analyse homologous integration using circular (pyr $\left.G^{*}\right)$ or linear DNA fragments in wild type or ku70 strains to clarify this have not been reported. These drawbacks make the construction of $A$. niger strains with targeted integration, such as of reporter constructs, a time consuming and laborious exercise.

In this study, a new pyrG targeting vector is presented to facilitate the construction of strains in which a reporter construct or another gene of interest is targeted to the pyrG locus, which is named pyrG*** ${ }^{* *}$ pyrG double star). The targeting vector (pMA334) is schematically depicted in Figure 2A and consists of a $5^{\prime}$ truncated non-functional pyrG gene, the pyrG 3' UTR, a unique NotI site, and a 3' pyrG flanking region. The position of the NotI site has been chosen directly behind the end of the 3' UTR of the pyrG mRNA and is based on RNA seq data (personal communication with P. Punt). The NotI site can be used to clone a particular DNA fragment (e.g. promoter reporter construct) in the targeting vector. Transformation of the linear DNA fragment will only result in a functional pyrG gene when the targeting vector integrates at the pyrG locus via a double cross over event (Figure 2B). The first cross over must occur between the 5' end of the truncated pyrG gene on the plasmid and the pyrG mutation in AB4.1. The second cross over must occur at the 3' flank for a complete integration of the cassette. In theory, a double crossover event could also occur between the 5' truncated nonfunctional pyrG gene and the pyrG 3' UTR, giving rise to pyrG prototrophic transformants that do not contain the reporter gene.

To test the efficiency of the pyrG ${ }^{* * *}$ targeting system, the luciferase reporter gene mluc [12] was cloned behind the constitutive gpdA promoter and ligated into targeting vector pMA334, giving plasmid pMA349 (Figure 2A). Linear DNA was isolated by digestion of pMA349 using $A s c \mathrm{I}$ and after purification, $20 \mu \mathrm{g}$ of DNA was transformed [5] into A. niger strain AB4.1 (pyrG ${ }^{-}$) (for strains and primers used in this study, see Table 1 and Table 2 respectively), resulting in 6 primary transformants. To check if integration of the reporter construct on the pyrG locus has occurred, all transformants were purified and analysed by Southern blot (Figure 3A). The result of the Southern blot analysis shows that 4 out of 6 transformants contain the reporter construct at the pyrG locus, while the other 2 transformants have a wild-type pyrG locus. The luciferase activity of these transformants was determined in a lux activity assay (Figure 3B), and only the strains that contain the reporter construct show lux activity.

In the pyrG ${ }^{* * *}$ system, the reporter construct has to integrate at the pyrG locus via homologous integration. In order to test the performance of the pyrG $G^{* *}$ system in a $k u 70^{-}$background, strain MA169.4 $\left(\right.$pyrG $\left.^{-}, k u 70^{-}\right)$was 


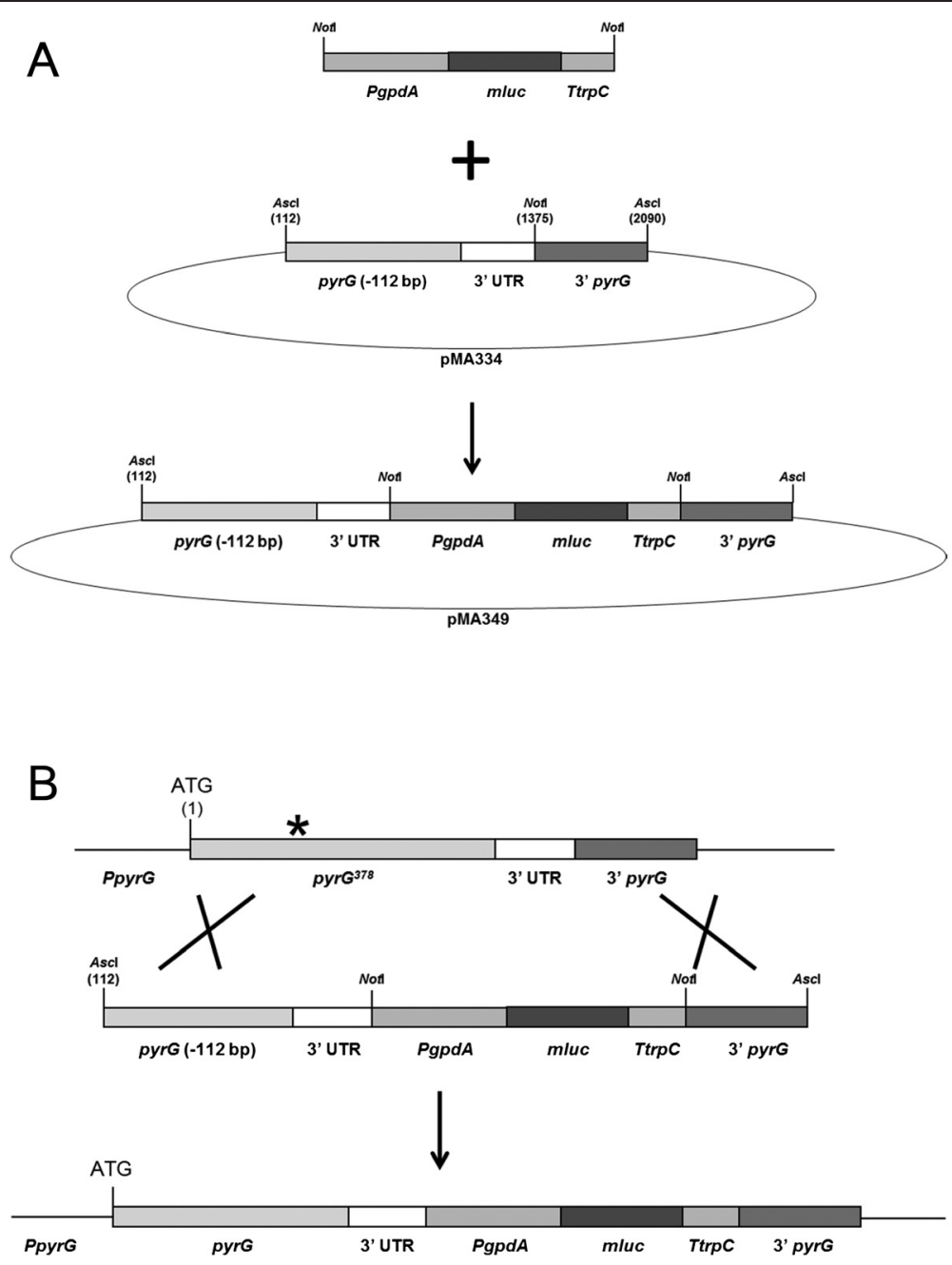

Figure 2 Schematic representation of integration of a reporter construct after a double crossover event using the pyrG** targeting system.

A) The truncated pyrG gene (-112) + 3' UTR fragment (1255 bp) was amplified by PCR using primers ABpyrGP12f and ABpyrGP10r. The 3' pyrG fragment (684 bp) was amplified by PCR using primers ABpyrGP11f and ABpyrGP13r. Both PCR products were digested (EcoRI-Notl for pyrG-3' UTR and Notl-Sstll for 3' pyrG) and ligated in EcoRI-Sstll opened pBluescriptSK, yielding plasmid pMA334. The mluc reporter cassette was obtained by PCR using SL1 and TtrpCP2rev-Notl as primers and pMA313 (containing PgpdA-mluc-TtrpC-AOpyrG, unpublished vector) as template. pMA334 was opened with Notl and the Notl digested Pgpdmluc-TtrpC fragment was inserted, giving plasmid pMA349. Both plasmids have been deposited at Fungal Genetic Stock Centre. pMA349 was digested with Ascl to release the complete $p y r G^{* *}$ targeting transformation DNA. B) Integration of the $p y r G^{* *}$ targeting construct via a double cross over at the pyrG locus.

Table 1 Strains used in this study

\begin{tabular}{llll}
\hline Strain & Genotype & Description & Reference \\
\hline N402 & cspA1 & derivative of N400 & {$[14]$} \\
AB4.1 & cspA1, pyrG378 & UV mutant of N402 & {$[1]$} \\
MA169.4 & cspA1, pyrG378, & ku70 disruption in AB4.1 & {$[8]$} \\
& kuSA::DR-amdS-DR & & \\
MA317.1-6 & cspA1, PgpdA-mluc- & PgpdA-mluc-TtrpC on & This study \\
& TtrpC on pyrG locus & pyrG locus in AB4.1 & \\
MA565.1-66 & cspA1, kusA:DR-amdS-DR, & PgpdA-mluc-TtrpC on & This study \\
& $\begin{array}{l}\text { PgpdA-mluc-TtrpC on } \\
\text { pyrG locus }\end{array}$ & pyrG locus in MA169.4 & \\
\hline
\end{tabular}

Table 2 Primers used in this study

\begin{tabular}{|c|c|c|}
\hline Primer name & Sequence $5^{\prime}-3^{\prime}$ & Used for \\
\hline $\begin{array}{l}\text { ABpyrGP12for- } \\
\text { EcoRI-Ascl }\end{array}$ & $\begin{array}{l}\text { CGGAATTCGG CGCGCCCGGC } \\
\text { TGACGTTACC ACCACT* }\end{array}$ & $\begin{array}{l}\text { pyrG-3' UTR PCR } \\
\text { (Figure 2A) }\end{array}$ \\
\hline ABpyrGP10rev-Notl & $\begin{array}{l}\text { AAGGAAAAAA GCGGCCGCAG } \\
\text { TCAGACCTAA TGCCTCGGG }\end{array}$ & $\begin{array}{l}\text { pyrG-3' UTR PCR } \\
\text { (Figure 2A) }\end{array}$ \\
\hline ABpyrGP11for-Notl & $\begin{array}{l}\text { AAGGAAAAAA GCGGCCGCCG } \\
\text { TCGCGTGATA AGGGTTG }\end{array}$ & $\begin{array}{l}\text { 3' pyrG PCR } \\
\text { (Figure } 2 A \text { ) }\end{array}$ \\
\hline $\begin{array}{l}\text { ABpyrGP13rev- } \\
\text { Sacl-Ascl }\end{array}$ & $\begin{array}{l}\text { CGAGCTCGGC GCGCCTCGGG } \\
\text { TCAATTTCCT CTGTTG }\end{array}$ & $\begin{array}{l}\text { 3' pyrG PCR } \\
\text { (Figure 2a) }\end{array}$ \\
\hline SL1 & $\begin{array}{l}\text { ATTTGCGGCC GCAGAACGCC } \\
\text { GAGAAGAACT GG }\end{array}$ & $\begin{array}{l}\text { PgpdA-mluc PCR } \\
\text { (Figure 2A) }\end{array}$ \\
\hline TtrpCP2rev-Notl & $\begin{array}{l}\text { AAGGAAAAAA GCGGCCGCTC } \\
\text { TAGAAAGAAG GATTACCTC }\end{array}$ & $\begin{array}{l}\text { PgpdA-mluc PCR } \\
\text { (Figure 2A) }\end{array}$ \\
\hline
\end{tabular}

*Relevant restriction sites are shown in italic. 


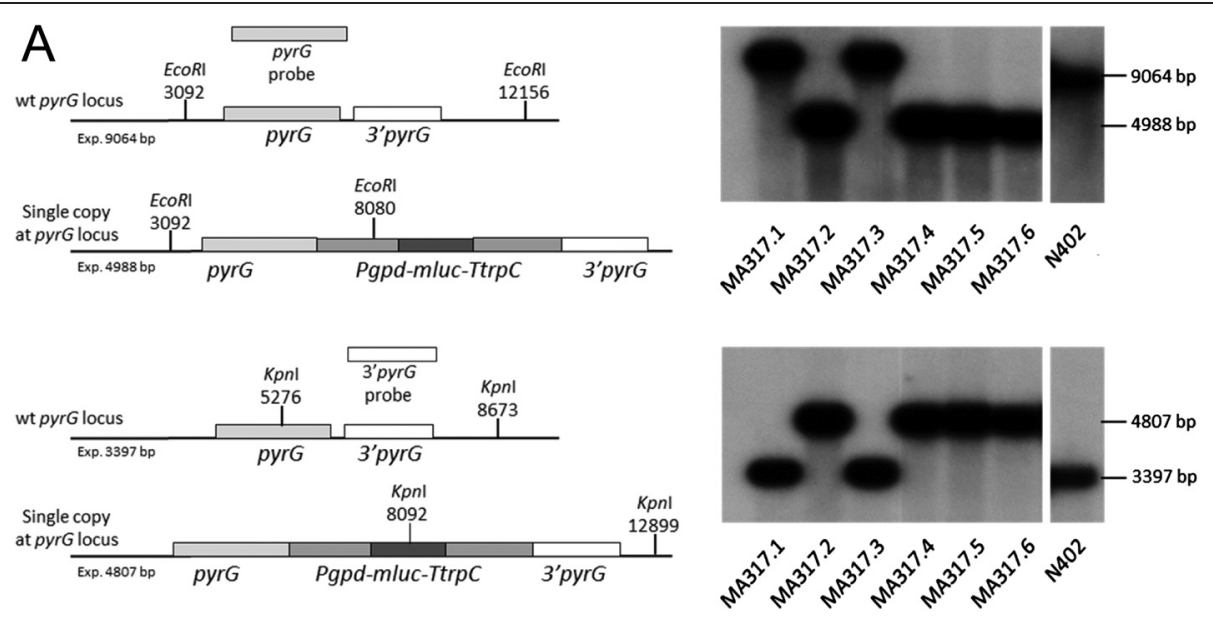

B

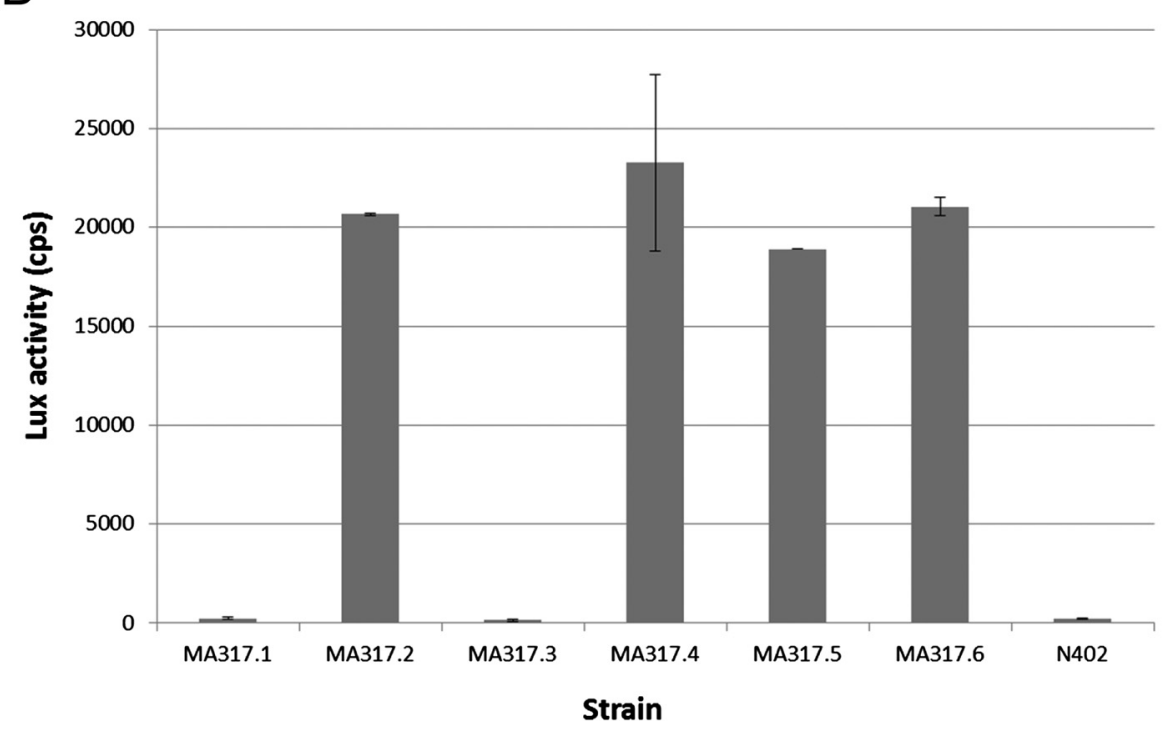

Figure 3 Analysis of $A$. niger MA317 transformants containing the Pgpd-mluc reporter construct using the pyrG $G^{* *}$ targeting method. A) Southern blot analysis. Genomic DNA was restricted with EcoRI or Kpnl and size fractioned by electrophoresis on a $1.0 \%$ agarose gel. For hybridisation, ${ }^{32}$ P-labelled pyrG probe (1255 bp, Figure 2A) or 3' pyrG probe (684 bp, Figure 2A) were used. When digested with EcoRl and using the pyrG probe (upper panel), a signal of $9.0 \mathrm{~kb}$ corresponds with the wild-type pyrG locus, while a signal of $4.9 \mathrm{~kb}$ corresponds with integration of the Pgpd-mluc cassette at the pyrG locus. When digested with Kpnl and using the 3' pyrG probe (lower panel), a signal of $3.3 \mathrm{~kb}$ corresponds with the wild-type pyrG locus, while a signal of $4.8 \mathrm{~kb}$ corresponds with integration of the Pgpd-m/uc cassette at the pyrG locus. Strains MA317.1 and MA317.3 have the wild-type pyrG locus, while strains MA317.2 and MA317.4-6 contain the Pgpd-m/uc cassette at the pyrG locus. B) Lux activity assay. The lux activity assay described by Meyer et al. [12] has been slightly modified. Briefly, $100 \mu \mathrm{L}$ of $2 \times$ Minimal Medium [5] with $0.006 \%$ yeast extract $(\mathrm{w} / \mathrm{v}), 76 \mu \mathrm{L}$ deionized water, $4 \mu \mathrm{L} 25 \mathrm{mM}$ luciferin (Promega, E1605) and $20 \mu \mathrm{L}$ spore suspension $\left(7.5^{*} 10^{5} \mathrm{spores} / \mathrm{mL}\right.$ ) was pipetted together (in triplicate) in a well of a white, clear bottom, 96 wells plate (Greiner Bio-one, ref 655095) and incubated for 24 hours at $30{ }^{\circ} \mathrm{C}$ in the EnSpire Multiplate Reader (Perkin) with continuous measuring of lux and OD. Lux activities after $16 \mathrm{~h}$ of incubation are shown here. Strains MA317.1 and MA317.3 have no lux activity, while strains MA317.2 and MA317.4-6 show comparable lux activities.

transformed with $10 \mu \mathrm{g}$ of linear DNA, isolated by digestion of plasmid pMA349 with AscI. In total 66 primary transformants were obtained and purified. These transformants were analysed for their luciferase activity in a lux assay (data not shown), resulting in 51 out of 66 (77\%) strains that show lux activity. Southern blot analysis (data not shown) of 15 selected strains showed that 13 strains, which showed comparable lux activities in the lux assay, contain the lux reporter construct at the $p y r G$ locus. In the other two strains, that were negative in the lux assay, the reporter construct was not present. No ectopic integrations were detected in these 15 transformants. 
In the experiments described above, the results indicate that the $\operatorname{pyr} \mathrm{G}^{* *}$ targeting system is both useful in wild-type and $k u 70^{-}$strains, even though the transformation frequency in the wild-type strain is much lower. It is likely that this lower frequency of transformation is due to the ectopic integration of the cassette, which does not result in transformants as this integration does not reconstitute the $p y r G$ gene.

The new targeting system has recently been successfully used in two independent studies in our laboratory. In the first study (A-M Burggraaf-van Welzen, unpublished results) 4 different $k u 70^{-}$strains and 2 different reporter genes were used. Out of 28 transformants analysed, 23 transformants contained the reporter construct at the pyrG locus (82\%). In the second study (J. Niu, unpublished results), a $\Delta k u 70$ strain was transformed with 6 different reporter constructs. Out of 122 primary transformants analysed, 105 transformants contained the reporter construct (86\%). Southern analysis of 24 transformants (four of each construct) confirmed integration at the $p y r G$ locus in all transformants analysed. These studies further confirm the efficiency and ease at which transformants with targeted integrations are obtained.

The described method to obtain transformants with targeted integration is not restricted to $p y r G$ mutants, but can also be used for other auxotrophic markers. Prerequisite is that the mutation in the auxotrophic marker is determined to allow design of the targeting cassette.

\section{Availability of supporting data}

The data set supporting the results of this article is included within the article. Plasmids and plasmids maps and DNA sequences are deposited at Fungal Genetics Stock Centre.

\section{Competing interests}

The authors declare that they have no competing interests.

\section{Authors' contributions}

MA carried out the molecular genetic studies. MA and EL designed and carried out the luciferase experiments. MA and AR designed the study and drafted the manuscript. All authors contributed to the writing. All authors read and approved the final manuscript.

\section{Acknowledgements}

We thank Anne-Marie Burggraaf-van Welzen, Jiachen Cui and Jing Niu for sharing unpublished results. We thank Peter Punt and Cees van den Hondel for helpful discussions. The plasmids pMA334 and pMA349 are deposited at Fungal Genetics Stock Centre (www.fgsc.net) and we thank the FGSC for making them available.

Received: 13 February 2015 Accepted: 26 February 2015

Published online: 14 March 2015

\section{References}

1. van Hartingsveldt W, Mattern IE, van Zeijl CM, Pouwels PH, van den Hondel CAM. Development of a homologous transformation system for Aspergillus niger based on the pyrG gene. Mol Gen Genet. 1987;206(1):71-5.
2. Osmani AH, Oakley BR, Osmani SA. Identification and analysis of essential Aspergillus nidulans genes using the heterokaryon rescue technique. Nat Protoc. 2006;1:2517-26.

3. d'Enfert C. Selection of multiple disruption events in Aspergillus fumigatus using the orotidine-5'-decarboxylase gene, $p y r G$, as a unique transformation marker. Curr Genet. 1996;30:76-82.

4. Boeke JD, LaCroute F, Fink GR. A positive selection for mutants lacking orotidine-5'-phosphate decarboxylase activity in yeast: 5-fluoro-orotic acid resistance. Mol Gen Genet. 1984;197:345-6.

5. Arentshorst M, Ram AFJ, Meyer V. Using non-homologous end-joiningdeficient strains for functional gene analyses in filamentous fungi. Methods Mol Biol. 2012;835:133-50.

6. de Ruiter-Jacobs YM, Broekhuijsen M, Unkles SE, Campbell El, Kinghorn JR, Contreras $\mathrm{R}$, et al. A gene transfer system based on the homologous pyrG gene and efficient expression of bacterial genes in Aspergillus oryzae. Curr Genet. 1989;6:159-63.

7. Meyer V, Arentshorst M, El-Ghezal A, Drews AC, Kooistra R, van den Hondel CAM, et al. Highly efficient gene targeting in the Aspergillus niger kusA mutant. J Biotechnol. 2007;128:770-5.

8. Carvalho NDSP, Arentshorst M, Kwon MJ, Meyer V, Ram AFJ. Expanding the ku70 toolbox for filamentous fungi: establishment of complementation vectors and recipient strains for advanced gene analyses. Appl Microbiol Biotechnol. 2010;87:1463-73.

9. van Gorcom RFM, van den Hondel CAM. Expression analysis vectors for Aspergillus niger. Nucleic Acids Res. 1988;16:9052.

10. Damveld RA, van Kuyk PA, Arentshorst M, Klis FM, van den Hondel CAM, Ram AFJ. The Aspergillus niger MADS-box transcription factor RImA is required for cell wall reinforcement in response to cell wall stress. Fungal Genet Biol. 2005;42:165-77.

11. Carvalho NDSP, Arentshorst M, Kooistra R, Stam H, Sagt CM, van den Hondel CAM, et al. Effects of a defective ERAD pathway on growth and heterologous protein production in Aspergillus niger. Appl Microbiol Biotechnol. 2011;89:357-73.

12. Meyer V, Wanka F, van Gent J, Arentshorst M, van den Hondel CAM, Ram AFJ. Fungal gene expression on demand: an inducible, tunable, and metabolism-independent expression system for Aspergillus niger. Appl Environ Microbiol. 2011;77:2975-83.

13. Carvalho NDSP, Arentshorst M, Weenink XO, Punt PJ, van den Hondel CAM, Ram AFJ. Functional YFP tagging of the essential GDP-mannose transporter reveals an important role for the secretion related small GTPase SrgC protein in maintenance of Golgi bodies in Aspergillus niger. Fungal Biol. 2011;115:253-64

14. Bos CJ, Debets AJ, Swart K, Huybers A, Kobus G, Slakhorst SM. Genetic analysis and the construction of master strains for assignment of genes to six linkage groups in Aspergillus niger. Curr Genet. 1988;14:437-43.

\section{Submit your next manuscript to BioMed Central and take full advantage of:}

- Convenient online submission

- Thorough peer review

- No space constraints or color figure charges

- Immediate publication on acceptance

- Inclusion in PubMed, CAS, Scopus and Google Scholar

- Research which is freely available for redistribution 